\title{
Electric power billing analysis via load and power hyperboloids in aviculture companies
}

\author{
Camila Pires Cremasco Luís Roberto Almeida Gabriel Filho \\ UNESP - Univ Estadual Paulista, Campus de Tupã, Laboratório de Matemática Aplicada e \\ Computacional \\ 17602-496, Tupã, SP \\ E-mails: cpcremasco@ibb.unesp.br, gabrielfilho@tupa.unesp.br
}

Luiz Roberto Almeida Gabriel

Faculdade de Ciências e Tecnologia, UNESP - Univ Estadual Paulista

19060-900, Presidente Prudente, SP

E-mail: gabriel@fct.unesp.br

Helenice de Oliveira Florentino Silva

Instituto de Biociências, UNESP - Univ Estadual Paulista, 18618-970, Botucatu, SP

E-mail: helenice@ibb.unesp.br

\section{Fernando Ferrari Putti}

Faculdade de Ciências Agronômicas, UNESP - Univ Estadual Paulista,

18.610-307, Botucatu, SP

E-mail: fernandoputti@tupa.unesp.br

\begin{abstract}
The region of Bastos-SP is responsible for a large part of the Brazilian egg production. Many of its poultry farms produce bird feed by grinding corn and soybeans using electric engines which are often oversized. In order to analyze the use of such power, there are power (pf) and load (lf) factors that indicate its efficiency and rationality. This study aimed at developing mathematical models to evaluate a company's power use through the volumes of solids. Such models are referred to as Load and Power Hyperboloids. It is an innovative methodology that has been in several studies on energy efficiency is always of great importance to estudados. $O$ cases this goal was analyze these models, an egg-laying aviculture company (poultry farm) in Bastos-SP Brazil was evaluated no period de 3 anos. In this illustration, the load and power factors remained within limits [0.11, 0.21] and [0.69, 1]. For this company, the solid volume calculated with the proposed methodology was Vc $=77.6$ u.c. Whereas the Total Useful Volume, representing the volume in the domain with limits over 1, was Vtu $=450.6$ u.c., it was concluded that it is possible to improve power use by $83 \%$, which can be achieved by applying the procedures herein proposed in order to increase $p f$ and lf.
\end{abstract}

Keywords: power factor, load factor, Load and Power Hyperboloid.

\section{Introduction}

Many authors have shown great care and worry with unnecessary power consumption, because this is a policies available for the reduction of carbon emission. Can also think that the gains in the efficiency of energy consumption results implies in effective reduction in the per unit price of energy services. So, has been given attention by policy makers to energy conservation.

Ultimately energy efficiency and energy conservation within the electricity sector attempt to achieve the same outcome, namely reduced electricity consumption, however each mechanism attempts to achieve this in two separate, but interrelated, ways [5].

Thus, this work propose a mathematical tool in order to evaluate the energy consumption of a company that uses multiple machines, with the aim to detect if there is unnecessary energy consumption, assisting in decision making and reduce electricity costs. The proposed mathematical model was applied in egg-laying aviculture company (poultry farm) in Bastos-SP Brazil. 
The region of Bastos-SP is responsible for a large part of the Brazilian egg production. The feed for chickens is produced by grinding corn and soybeans using electric engines, which are often oversized. This activity is responsible for a large part of the companies' power expenditure.

In order to evaluate the use of such power, there are power (pf) and load (lf) factors, which respectively indicate the efficiency and rationality of the way electric power is utilized. These factors are very useful and has been the subject of many research. Knowledge and management of these indices provides greater efficiency and safety facilities and equipment, while reducing the cost of electricity [10].

Some electric appliances, such as engines, in addition to consuming active power, also require reactive power, which is necessary to create the magnetic flow for proper functioning. Through the relation between these values, the mean power factor for a certain period is determined. Such factor is defined as the as the relation between active power and apparent or total power. It is the index that shows how much electric power is being transformed into other forms of energy. Power factor of the system should be equal or close to the unity. Low power factor means larger rating of equipment such as generators, transformers, etc. [1].

The literature reports the use of the load and power factor indexes in the determination of geometric models, as for instance [7], who evaluated the use of electric power in operations for vegetal oil refinement. This innovative and highly efficient methodology to study the energy efficiency of a company has already been used in various applications such as the analysis of the Rationalization of Energy Companies in provide Coffee and Analysis of consumption and electricity demand in agricultural implements company via hyperboloids of load and power..

This study aimed at developing geometric and differential mathematical models of the electric power consumption costs and demand for active and reactive power, referred to as Load and Power Hyperboloids, that can evaluate the efficiency and rationality of electric power use at an egg-laying aviculture company by using the volumes of solids.

\section{Material and methods}

In order to apply and illustrate the methodology proposed in the present study, the rationality and efficiency of electric power use by an aviculture company (poultry farm) located in the city of Bastos, SP, Brazil, was evaluated. The company's main activity is egg-laying aviculture.

Characterized as a large company, the poultry farm has approximately one million chickens that are sheltered in sheds during all phases, from the purchase of one-day-old chicks, going through the chicken phase until production and rebreeding.

Through the analysis of monthly electricity bills for the years 2005 to 2007 of the company under study, data referring to electric power use and concerning active and reactive consumption, demand and power factors were obtained.

The partial estimation of electric power cost is currently made by using data measured every 15 minutes and, by adding each part obtained in such measurements, the total monthly cost is obtained. The power factor and the load factor used by the electricity supplying company are obtained by estimating the arithmetic means at every 15 -minute measurement interval.

In this study, the monthly power factor was directly obtained from the descriptive report provided by the electricity supplying company whereas the monthly load factor was estimated through parameters that can also be found in the descriptive report.

In order to estimate the load factor, the relation between the mean demand $(\mathrm{kWh})$ and the maximum demand $(\mathrm{kWh})$ measured during an established period of time was used and expressed as $[3,6]$ :

$$
\text { Load Factor }=\frac{\text { Mean Demand }}{\text { Maximum Measured Demand }}
$$

or 


$$
\text { lf }=\frac{\text { Active Power }}{\text { time } \times \text { Demand }}
$$

For the company under study, its option for power billing using the green tariff was observed. Such tariff is to be used for clients with a demand lower than $500 \mathrm{~kW}$, with inclusion in Sub-group A4 (characterized by the binomial tariff structure with supply voltage of $2.3 \mathrm{kV}$ to $25 \mathrm{kV}$ ).

The main characteristic of the green tariff is the existence on a single power factor and of monthly loads for billing estimation. According to [4], the billing of electric power according to the green tariff is given by:

$$
\mathrm{F}= \begin{cases}\frac{0.92}{p f}\left(a_{1}+\frac{b}{730 l f}\right) c_{1}+\frac{0.92}{p f}\left(a_{2}+\frac{b}{730 l f}\right) c_{2}, & \text { if } 0<p f \leq 0.92 \\ \left(a_{1}+\frac{b}{730 l f}\right) c_{1}+\left(a_{2}+\frac{b}{730 l f}\right) c_{2}, & \text { if } 0.92<p f \leq 1\end{cases}
$$

where $a_{1}=\mathrm{CT}_{\mathrm{p}}, a_{2}=\mathrm{CT}_{\mathrm{opt}}, b=\mathrm{DT}, c_{1}=\mathrm{C}_{\mathrm{p}}, c_{2}=\mathrm{C}_{\mathrm{opt}}$ and:

$\mathrm{C}_{\mathrm{p}}, \mathrm{C}_{\mathrm{opt}}$ - active consumption at peak times and out of peak times, $\mathrm{kWh}$;

$\mathrm{CT}_{\mathrm{p}}, \mathrm{CT}_{\mathrm{opt}}$ - consumption tariff at peak times and out of peak times, $\mathrm{R} \$ / \mathrm{kWh}$;

DT - demand tariff, R\$/kW.

The mean consumption (active, active at peak times and out of peak times) was defined as the arithmetic mean of consumption in the months in the study period. The hour-seasonal tariffs used in the formulas were obtained by weighed averages as follows:

$$
\mathrm{T}=\frac{7 . \mathrm{T}_{\mathrm{S}}+5 \cdot \mathrm{T}_{\mathrm{U}}}{12}
$$

Where $\mathrm{T}$ is the tariff used in the billing formulas (representing $\mathrm{CT}_{\mathrm{p}}, \mathrm{CT}_{\mathrm{opt}}$ or DT), $\mathrm{T}_{\mathrm{D}}$ is the tariff in the dry season ( 7 months), and $\mathrm{T}_{\mathrm{W}}$ is the tariff in the wet season (5 months). For these calculations, the values provided by the power supplying company (Table 1) for Sub-group A4 were used.

Table 1. Electric power supply tariffs for the month of April 2013[2], provided by the NET inter-connected system.

\begin{tabular}{cccccc}
\hline & \multicolumn{4}{c}{ GREEN HOUR-SEASONAL TARIFF } \\
\hline \multirow{3}{*}{ SUB-GROUP } & \multirow{2}{*}{$\begin{array}{c}\text { DEMAND } \\
\text { (R\$/kW) }\end{array}$} & \multicolumn{3}{c}{ CONSUMPTION (R\$MWh) } \\
\cline { 3 - 6 } & & PEAK & \multicolumn{3}{c}{ OUT OF PEAK } \\
\hline A3a & 4.34 & 521.41 & 362,48 & 124.43 & PEAK \\
\hline A4 & 6.20 & 536.94 & 508,84 & 127.81 & 117.03 \\
\hline
\end{tabular}

With the electric power billing formula, it was possible to create regular parameterized surfaces and define them as Load and Power Hyperboloids. To that end, it was necessary to use concepts from differential geometry and from the local theory of [9].

For the evaluation concerning efficiency and rationality, volumes were determined from solids determined by the Load and Power Hyperboloid and regions in its domain determined with minimum $\left(p f_{1}\right)$ and maximum $\left(p f_{2}\right)$ power factor values in the period for the company's analysis, as well as the minimum $\left(l f_{1}\right)$ and maximum $\left(l f_{2}\right)$ load factor values. These solids were 
defined as Current Volume $(V c)$ and 1 Total Useful Volume $(V t u)$, and the expression 1 $V c / V_{T U}$ represents the possible improvement percent for power use that can be achieved by applying procedures for $p f$ and $l f$ increase.

\section{Results and discussion}

According witch equation (3), is possible make an function $f: U \rightarrow \mathfrak{R}^{3}$ such that,

$$
f(x, y)= \begin{cases}\left(x, y, \frac{0,92}{x}\left(a_{1}+\frac{b}{730 y}\right) c_{1}+\frac{0,92}{x}\left(a_{2}+\frac{b}{730 y}\right) c_{2}\right), & \text { if } 0<x<0,92 \\ \left(x, y,\left(a_{1}+\frac{b}{730 y}\right) c_{1}+\left(a_{2}+\frac{b}{730 y}\right) c_{2}\right), & \text { if } 0,92<x<1\end{cases}
$$

which rules a company's electric billing according to the green tariff, is a regular parameterized surface [2], in which:

$$
\begin{aligned}
& U=\left\{(x, y) \in \mathfrak{R}^{2}: 0<x<1,0<y<1, x \neq 0.92\right\} ; \\
& x=p f-\text { power factor; } \\
& y=l f \text { - load factor. }
\end{aligned}
$$

By defining function $g: U_{1} \rightarrow \Re^{3}$ as the similar formation law to that of $f$ by replacing domain $0.92<x<1$ for $0.92<x \leq 1$ and $\mathrm{U}$ for $U_{1}=\left\{(x, y) \in \mathfrak{R}^{2}: 0<x \leq 1,0<y \leq 1\right\}$; sub-set $g\left(U_{1}\right)$ of $\mathfrak{R}^{3}$ is denominated as the V-Load and Power Hyperboloid. The reference to such Hyperboloid as "surface" is made only for the part in which function $g$ is restricted to subset $U\left(U \subset U_{1}\right)$, and identification $\left.g\right|_{U}=f$ is considered.

According to [8], the Current Volume $\left(V_{C}\right)$ is the volume of the solid (Figure 2) superiorly limited by the Load and Power V-Hyperboloid, inferiorly by plane $\mathrm{F}=0$ and laterally by planes $x=p f_{1}, x=p f_{2}, y=l f_{1}$ and $y=l f_{2}$. The Current Volume value is estimated by:

$$
\text { . } V_{A}=\int_{p f_{1}}^{p f_{2}} \int_{l f_{1}}^{l f_{2}} f(x, y) d y d x
$$

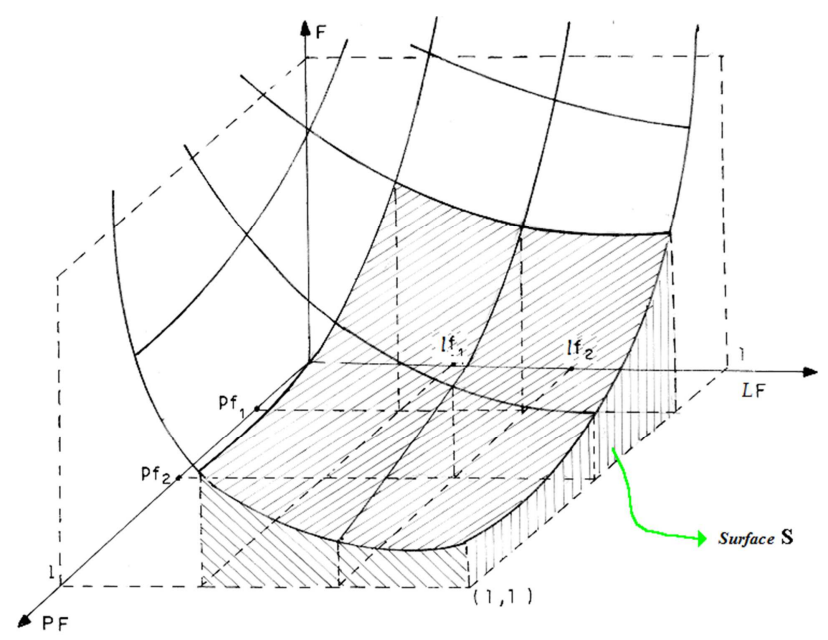

Figure 2. Solid limited by the Load and Power V-Hyperboloid, by plane $F=0$ and laterally by planes $x=p f_{1}, x=p f_{2}, y=l f_{1}$ and $y=l f_{2}$.

There are three cases to be considered in relation to the limiting values of the power factor: 
(i) If $p f_{2} \leq 0.92, \quad V_{A}=\int_{p f_{1}}^{p f_{2}} \int_{l f_{1}}^{l f_{2}} \frac{0.92}{x}\left(\left(a_{1}+\frac{b}{730 y}\right) c_{1}+\left(a_{2}+\frac{b}{730 y}\right) c_{2}\right) d y d x$

(ii) If $p f_{1}<0.92<p f_{2}, \quad V_{A}=\int_{p f_{1}}^{0.92} \int_{l f_{1}}^{l f_{2}} \frac{0.92}{x}\left(\left(a_{1}+\frac{b}{730 y}\right) c_{1}+\left(a_{2}+\frac{b}{730 y}\right) c_{2}\right) d y d x+$

$$
+\int_{0.92}^{p f_{2}} \int_{l f_{1}}^{l f_{2}}\left(\left(a_{1}+\frac{b}{730 y}\right) c_{1}+\left(a_{2}+\frac{b}{730 y}\right) c_{2}\right) d y d x
$$

(iii) If $p f_{1} \geq 0.92, \quad V_{A}=\int_{p f_{1}}^{p f_{2}} \int_{l f_{1}}^{l f_{2}}\left(\left(a_{1}+\frac{b}{730 y}\right) c_{1}+\left(a_{2}+\frac{b}{730 y}\right) c_{2}\right) d y d x$

The "Total Useful Volume $\left(V_{T U}\right)$ " is obtained in a similar fashion to that for the Current Volume, with upper limits by planes $x$ and $y$, both equal to 1 , that is:

$V_{A}=\int_{p f_{1}}^{1} \int_{l f_{1}}^{1} f(x, y) d y d x$

In this case, only two situations are considered in relation to the power factor values:

(i) If $p f_{1}<0.92$,

$$
\begin{aligned}
& V_{T U}=\int_{p f_{1}}^{0.92} \int_{l f_{1}}^{1} \frac{0.92}{x}\left(\left(a_{1}+\frac{b}{730 y}\right) c_{1}+\left(a_{2}+\frac{b}{730 y}\right) c_{2}\right) d y d x+ \\
& +\int_{0.92}^{1} \int_{l f_{1}}^{1}\left(\left(a_{1}+\frac{b}{730 y}\right) c_{1}+\left(a_{2}+\frac{b}{730 y}\right) c_{2}\right) d y d x \\
& V_{A}=\int_{p f_{1}}^{1} \int_{l f_{1}}^{1}\left(\left(a_{1}+\frac{b}{730 y}\right) c_{1}+\left(a_{2}+\frac{b}{730 y}\right) c_{2}\right) d y d x
\end{aligned}
$$

(ii) If $p f_{1} \geq 0.92$,

\begin{tabular}{|c|c|c|c|c|c|}
\hline \multicolumn{6}{|c|}{ GREEN HOUR-SEASONAL TARIFF } \\
\hline \multirow{3}{*}{ SUB-GROUP } & \multirow{3}{*}{$\begin{array}{c}\text { DEMAND } \\
(\mathbf{R} \$ / \mathbf{k W})\end{array}$} & \multicolumn{4}{|c|}{ CONSUMPTION (R\$/MWh) } \\
\hline & & \multicolumn{2}{|c|}{ PEAK } & \multicolumn{2}{|c|}{ OUT OF PEAK } \\
\hline & & DRY & WET & DRY & PEAK \\
\hline $\mathrm{A} 3 \mathrm{a}$ & 4.34 & 521.41 & 362,48 & 124.43 & 102.01 \\
\hline A4 & 6.20 & 536.94 & 508,84 & 127.81 & 117.03 \\
\hline
\end{tabular}

Table 1. Electric power supply tariffs for the month of April 2013[2], provided by the NET inter-connected system.

Considering the studied company's classification in Sub-group 4, from Table 1 and Equation 4, it was possible to determine the values considered for estimating the consumption tariff at peak times $\mathrm{CT}_{\mathrm{p}}=0.5866 \mathrm{R} \$ / \mathrm{kWh}$ and out of peak times $\mathrm{CT}_{\mathrm{opt}}=0.11221 \mathrm{R} \$ / \mathrm{kWh}$ as well as the demand tariff $\mathrm{DT}=6.20 \mathrm{R} \$ / \mathrm{kW}$.

Since, it was possible to calculate the mean values for active consumption at peak times $\mathrm{C}_{\mathrm{p}}=54.34$ and out of peak times $\mathrm{C}_{\mathrm{opt}}=15.27$, the minimum power factor $p f_{1}=0.69$ and maximum power factor $p f_{2}=1.00$, as well as those for the minimum load factor $l f_{1}=0.11$ and maximum load factor $l f_{2}=0.21$.

The need for change was observed at the end of the research, in order to improve the energy efficiency of engines. An alternative to increase this efficiency was the installation of capacitors in the system, which was done in the last year of the study provided good results in the use of electricity. The studies showed that the usable form of electricity must be performed 
by implementing and studies on the replacement of existing engines. These procedures should aim at increasing the load factor; However, the power factor need not be improved, since its maximum value, 1 , which is made possible with the installation of capacitors.

The functions that rules the electric power billing in the company is given by (Equation 5):

$$
f(x, y)= \begin{cases}\left(x, y, \frac{0.92}{x}\left(1260+\frac{90}{y}\right)\right), & \text { if } 0<x \leq 0.92 \\ \left(x, y, 1260+\frac{90}{y}\right), & \text { if } 0.92<x \leq 1\end{cases}
$$

and the associated surface generates the Load and Power V-Hyperboloid for the egg-laying aviculture company under study (Figure 3).

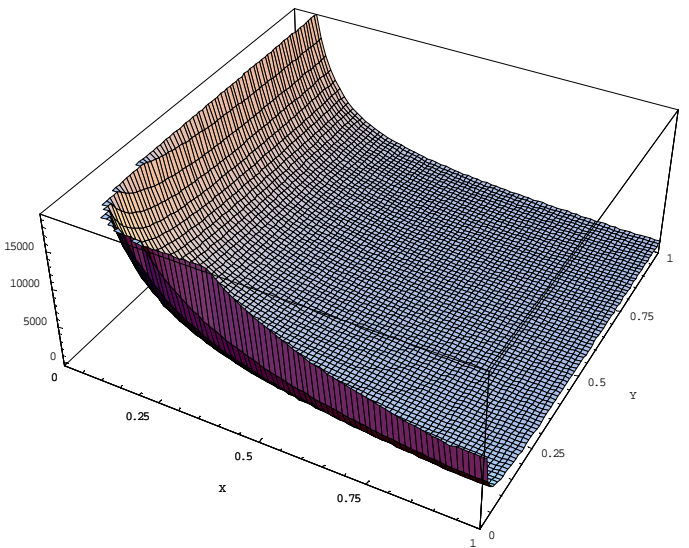

(a)

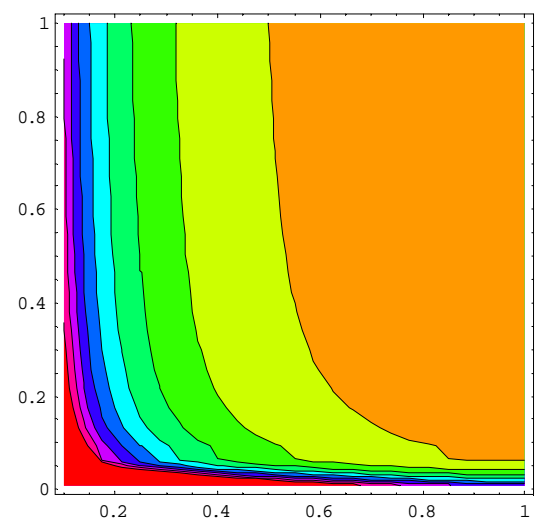

(b)

Figure 3. (a)Draft of the Load and Power V-Hyperboloid for the egg-laying aviculture company under study, (b) Contour map for the Load and Power V-Hyperboloid formed by its level curves. follows:

Given that $p f_{1}<0.92<p f_{2}$, the Current Volume could be calculated by Equation 8 as

$$
V_{A}=\int_{0.69}^{0.92} \int_{0.11}^{0.21} \frac{0.92}{x}\left(1230+\frac{90}{y}\right) d y d x+\int_{0.92}^{1} \int_{0.11}^{0.21}\left(1230+\frac{90}{y}\right) d y d x=85 \text { u.c. }
$$

Given that $p f_{1}<0.92$ by Equation 1, the Total Useful Volume is obtained as follows:

$$
V_{T U}=\int_{0.69}^{0.92} \int_{0.11}^{1} \frac{0.92}{x}\left(1260+\frac{90}{y}\right) d y d x+\int_{0.92}^{1} \int_{0.11}^{1}\left(1260+\frac{90}{y}\right) d y d x=480.5 \text { u.c. }
$$

Given that $V_{C} / V_{T U}=17,7 \%$, the Current $\left(V_{C}\right)$ represents $17,7 \%$ of the Total Useful Area $\left(V_{T U}\right)$, that is, $V_{C}=17,7 \% V_{T U}$. Hence, for this egg-laying company, it is possible to reduce the electric power consumption bill and equivalent demand to $82,3 \%(1-17 \%)$ of the Total Useful Volume by the Load and Power V-Hyperboloid.

\section{Conclusions}

This study proposes mathematical models that can help with the evaluation of electric power use in companies through the solid volumes referred to as Load and Power Hyperboloids. It was observed that the methodology proposed has an innovative character, and that it is highly applicable in any company in the country, thus showing to be an efficient method for analyzing forms of electric power use. 


\section{References}

[1] ÅDNANES, A.K. Maritime electrical installations and diesel electric propulsion, tutorial Report/Textbook, ABB Marine AS, Oslo, Norway, 2003.

[2] AGÊNCIA NACIONAL DE ENERGIA ELÉTRICA (BRASIL). Tarifas de fornecimento de energia elétrica / São Paulo, 2013. http://www.aneel.gov.br/area.cfm?idPerfil=2).

[3] CARMO, M. P. do; Differential Geometry of Curves and Surfaces. Prentice-Hall, Inc., Rio de Janeiro, Brazil, 1976.

[4] CREMASCO, C. P. Aplicação da lógica fuzzy para avaliação do faturamento do consumo de energia elétrica e demanda de uma empresa de avicultura de postura. $97 \mathrm{f}$. Tese (Doutorado em Agronomia / Energia na Agricultura) - Universidade Estadual Paulista, Faculdade de Ciências Agrárias, Botucatu, 2008.

[5] CROUCHER, M. Potential problems and limitations of energy conservation and energy efficiency, Energy Policy, Volume 39, Issue 10, October 2011, Pages 5795-5799, ISSN 0301-4215, 10.1016/j.enpol.2011.07.011.

(http://www.sciencedirect.com/science/article/pii/S0301421511005349)

[6] ERICKSON, R.; MADIGAN, M.; SINGER, S.; "Design of a simple high-power-factor rectifier based on the flyback converter", in Applied Power Electronics Conference and Exposition, 1990, pp. 792-801.

[7] GABRIEL, L. R. A. Análise da racionalização do uso de energia elétrica através de Hiperbolóides de Carga e Potência em operações de processamento de arroz (Oryza Sativa, L.). 289 f. Tese (Doutorado em Agronomia / Energia na Agricultura) Universidade Estadual Paulista, Faculdade de Ciências Agrárias, Botucatu, 1994.

[8] GABRIEL, L. R. A. Análise do faturamento do consumo de energia elétrica e demanda através de Hiperbolóides de Carga e Potência em operações de refino de óleo vegetal.

312 f. Tese (Livre Docência em Matemática) - Universidade Estadual Paulista, Faculdade de Ciências e Tecnologia, Presidente Prudente, 1997.

[9] KOLAR, I., SLOVAK, J., MICHOR. P. W. Natural operations in differential geometry. Springer-Verlag, Berlin, Heidelberg, New York, 1993

[10] MOHAN, N.; TORE, M. U. ; ROBBINS W.P. Power Electronics converters, Applications and Desingn, Third Edition, John Wiley, 2003.

[11] SINGH, S. N. Electric Power Generation Transmission ond Distribution. Prentice-Hall, New Delhi, Sixth Printing, 2006.

[12] SPIVAK, M. A comprehensive introduction to differential geometry. Publish or Perish, Houston, 1979. 